\title{
A key role for nuclear cardiac imaging in evaluating and managing patients with heart failure
}

\author{
Mark I. Travin, MD, FASNC, ${ }^{\mathrm{a}, \mathrm{b}}$ and Gayathri Kamalakkannan, MD ${ }^{\mathrm{a}, \mathrm{b}}$
}

See related article, pp. 1007-1016

Congestive heart failure (CHF, HF) is a major health problem in the United States and much of the western world. More than 6 million Americans over age 20 have HF, with $1 / 5$ people over 40 likely to develop HF sometime during their lives. ${ }^{1}$ Despite significant advancements in evaluation and management, the death rate remains high, with about $50 \%$ of HF patients dying in 5 years, and HF mentioned as a contributing factor in $1 / 9$ death certificates. ${ }^{2,3}$

A variety of methods are used to assess patients with HF, including standard clinical techniques, i.e., history, physical examination, and laboratory measurements; a variety of non-invasive imaging procedures that include chest $\mathrm{x}$-ray, echocardiography, equilibrium radionuclide angiography (ERNA), myocardial perfusion imaging with ECG-gated SPECT, cardiac CT methods, cardiac magnetic resonance imaging, and invasive procedures such as right and left heart catheterization, and coronary angiography. These methods diagnose HF, determine a likely etiology, classify its severity, identify additional contributing factors, and guide patient management in terms of remedying reversible causes, improving symptoms and patient well-being, and preventing additional adverse events ranging from frequent recurrent HF hospitalizations to dangerous cardiac arrhythmias to death. Recent American College of Cardiology Foundation/American Heart Association (ACCF/AHA) Heart Failure guidelines

From the Division of Nuclear Medicine, Department of Radiology, ${ }^{\mathrm{a}}$ Division of Cardiology, Department of Medicine, ${ }^{\mathrm{b}}$ Montefiore Medical Center, Albert Einstein College of Medicine, Bronx, NY.

Reprint requests: Mark I. Travin, MD, FASNC, Division of Nuclear Medicine, Department of Radiology, Montefiore Medical Center, Albert Einstein College of Medicine, 111 E. 210th Street, Bronx, NY 10467-2490; mtravin@attglobal.net.

J Nucl Cardiol 2012;19:879-82.

$1071-3581 / \$ 34.00$

Copyright (c) 2012 American Society of Nuclear Cardiology.

doi:10.1007/s12350-012-9615-9 recommend comprehensive pharmacologic regimens, and describe when advanced mechanical device therapies such as biventricular pacemakers for cardiac resynchronization therapy (CRT), left ventricular assist devices (LVAD), and implantable cardiac defibrillators (ICD) should be considered, as well as when cardiac transplantation is the preferred option. ${ }^{4}$

Nevertheless, much remains unclear regarding the approach to patients with $\mathrm{HF}$, a condition expected to increase in prevalence in coming years as the population ages. ${ }^{5}$ In particular, many of the beneficial advanced mechanical device therapies are costly and have risks. It is important to wisely select which patients should receive them. An issue of particular focus is who should get an ICD. Based on several multicenter, prospective randomized clinical trials, the ACCF/AHA HF guidelines assign a Class IA recommendation for implantation of an ICD as primary prevention of sudden cardiac death (SCD) in patients with New York Heart Association (NYHA) Class II-III symptoms and a left ventricular ejection fraction (LVEF) $\leq 35 \% .^{4,6-8}$ At the same time, while trials report significant reductions in mortality with ICDs, the absolute decrease in death is relatively small, from about $5.6 \%{ }^{7}$ to $7.2 \%,{ }^{6}$ with $11^{7}$ to $14^{6}$ patients needing to receive an ICD to save 1 life. ${ }^{9}$ There are risks associated with an ICD, including a $4 \%$ postprocedural complication rate, ${ }^{10}$ infections, device malfunction, worsened quality of life, psychiatric problems, and life style restrictions. ${ }^{11,12}$ ICDs are expensive, about $\$ 28,000$ per device, not including ICD follow-up costs. ${ }^{13}$ Thus, current methods for choosing which patients receive an ICD have limitations, ${ }^{14}$ and using LVEF as a major deciding parameter appears flawed. ${ }^{15}$

A key way to identify patients who are best managed with advanced mechanical therapies such as an ICD, and/or who should be referred for cardiac transplant, is effective risk stratification, better if one can adjust predicted outcomes for clinical status changes, including when a device is added. Using databases from multiple large HF studies, survival scores have been developed incorporating combinations of clinical variables. One such model, the Seattle Heart Failure Model (SHFM), uses routinely collected demographic, imaging, laboratory, and therapeutic parameters to generate a 
score that determines the likely 1-5-year mortality, ${ }^{16,17}$ predicts the mode of death, i.e., SCD versus progressive $\mathrm{HF},{ }^{18}$ and measures potential improved survival with mechanical devices. ${ }^{19}$ In response to demonstration by SCD-HEFT (SCD in HF) ${ }^{6}$ of improved survival with an ICD in Class II-III NYHA patients with LVEF $\leq 35 \%$, a modified version of the model, i.e., SHFM-D was developed..$^{20}$ In particular, SHFM-D can identify not only subgroups of patients for whom ICD placement is most beneficial but also a subgroup that, while at high risk overall mortality, is so unlikely to have SCD that an ICD has no benefit. SHFM-D appears better than LVEFbased current approaches for deciding on an ICD.

Another technique consistently found to effectively risk stratify patients with advanced HF is cardiac imaging with ${ }^{123} \mathrm{I}-m \mathrm{IBG}$ (metaiodobenzylguanidine), a radionuclide analogue of norepinephrine that provides information on the health of cardiac sympathetic innervation. ${ }^{21,22}$ Most commonly, global cardiac uptake is measured on delayed planar images, expressed as a ratio of cardiac activity to background, i.e., the heart-tomediastinal ratio $(\mathrm{H} / \mathrm{M})$. Among the first to recognize ${ }^{123} \mathrm{I}-m \mathrm{IBG}$ imaging as a potentially useful risk stratifying tool for patients with HF was Merlet et al, ${ }^{23}$ finding that $\mathrm{H} / \mathrm{M}$ was independent of and superior to cardiac size on chest $\mathrm{x}$-ray, echocardiographic end-diastolic diameter, and LVEF in predicting survival in patients with NYHA Class II-III symptoms and LVEF $<45 \%$. Subsequently, various small single-center studies reported the potential value of cardiac ${ }^{123}$ I- $m$ IBG imaging in HF patients, followed by a 290 patient multicenter retrospective reanalysis study ${ }^{24}$ and a 1,755 patient meta-analysis ${ }^{25}$ that strengthened the belief by many that ${ }^{123} \mathrm{I}-m \mathrm{IBG}$ imaging provides prognostic and therapeutic guiding value beyond standard clinical and laboratory parameters. These efforts culminated in the AdreView Myocardial Imaging for Risk Evaluation in Heart Failure (ADMIRE-HF) trial, a prospective, multicenter, international study of 961 patients with NYHA Class II-III HF and LVEF $\leq 35 \% .{ }^{26}$ At 17 months, an $\mathrm{H} / \mathrm{M}<1.6$ more than doubled (from $15 \%$ to $37 \%$ ) the incidence of worsening CHF, life-threatening arrhythmias, and cardiac death. Subsequent multivariate analysis showed that $\mathrm{H} / \mathrm{M}$ was a predictor of cardiac and all-cause deaths independent of other clinical and image variables, including age, LVEF, and brain natriuretic peptide (BNP). ${ }^{27}$

In the manuscript by Ketchum et $\mathrm{al}^{28}$ appearing in this issue of the journal, the investigators examine enhancement of the risk stratification power of the SHFM-D model by the addition of ${ }^{123} \mathrm{I}-m \mathrm{IBG}$ parameters for patients enrolled in ADMIRE-HF. In this cohort, SHFM-D was again a significant predictor of adverse outcome. At the same time, the $\mathrm{H} / \mathrm{M}$ was an independent predictor of events, and added incremental risk stratification to
SHFM-D. When the authors dichotomized the patients by the median SHFM-D, each standard deviation (SD) increase in $\mathrm{H} / \mathrm{M}$ ratio was associated with increased mortality. This was especially true for the cohort of patients with an SHFM-D score above the median (88.5\% risk increase for each SD, $P<.0001$ ). Addition of the $\mathrm{H} / \mathrm{M}$ ratio was superior to SHFM-D alone in effectively reclassifying patients, with a $14.9 \%$ net reclassification improvement for patients who died, and a 7.9\% improvement for those who survived, with a net reclassification improvement of $22.7 \%$.

Evidence in the literature suggests that neurohormonal activation is a key factor in HF that is proarrhythmic and contributes to remodeling. Although some SHFN-D variables, such as serum sodium and systolic blood pressure indirectly incorporate the prognostic value of neurohormonal factors, direct sympathetic innervation imaging using $\mathrm{H} / \mathrm{M}$ is shown by the analyses of Ketchum et al to add important incremental risk stratification value. The additive prognostic utility of ${ }^{123}$ I- $m$ IBG imaging over SHFM-D should allow better selection of beneficial therapy.

What next? The manuscript by Ketchum et al adds to the wealth of available data consistently showing the strong and independent risk stratification ability of ${ }^{123}$ I- $m$ IBG imaging. Its prognostic power has just about always been found to be as good as, or better than, parameters such as LVEF and BNP upon which major therapeutic decisions are customarily made for $\mathrm{HF}$ patients. Nevertheless in the current era, for ${ }^{123} \mathrm{I}-m \mathrm{IBG}$ imaging to become part of the standard evaluation of $\mathrm{HF}$ patients, demonstration of effective risk stratification will not be sufficient-imaging will have to be shown to be reliably useful for key therapeutic decision-making and ultimately improve outcome. Despite the reported high negative predictive values for death if the $\mathrm{H} / \mathrm{M}$ ratio is above a certain value, many have expressed skepticism in using ${ }^{123} \mathrm{I}-m \mathrm{IBG}$ imaging to decide not to place an ICD in a patient who meets guidelines. Currently in the US, although ${ }^{123} \mathrm{I}-\mathrm{mIBG}$ is available it is not FDA approved for cardiac imaging, and therefore not reimbursable. The lack of convenient clinical availability has precluded large prospective studies that many say are required to show that imaging is a safe and effective way to decide on an ICD. There is concern that without such studies managing patients not in accordance with published guidelines is unwise, particularly because of the potential medical-legal implications of a patient meeting guidelines who, based on ${ }^{123} \mathrm{I}-m \mathrm{IBG}$ imaging does not receive an ICD, and then suffers a SCD.

However, it is important to consider the limitations of guidelines. ${ }^{29}$ In a critical discussion of practice guidelines, Diamond and Kaul write that they are "most often...constructed from a pastiche of expert consensus opinion, observational cohort studies, and randomized 
control trials," and "even when founded solely on direct empirical observations from well-designed randomized trials...the weighing of the evidence is inherently subjective and does not explicitly reflect the putative clinical importance of the wide spectrum of alternative outcomes and treatment effect." 30 Guidelines for ICD use as primary prevention derive largely from four large randomized studies: Multicenter Automatic Defibrillator Implantation Trial-II (MADIT-2), ${ }^{7}$ Defibrillator in Acute Myocardial Infarction Trial (DINAMIT), ${ }^{8}$ Defibrillators in Non-ischemic Cardiomyopathy Treatment Evaluation (DEFINITE) $^{31}$ and SCD-HeFT. ${ }^{6}$ From these, LVEF has become a principal variable for deciding who should receive a device. However, as described by Myerburg, " 'these trials, especially MADIT-II and SCD-HEFT, had broad enrollment criteria, with limited stratification of the study populations, and have shown relatively small absolute improvements in the outcomes.", 32 Differences among EF entry criteria were large, and most enrolled patients had EFs well below the threshold ultimately used in guidelines. Buxton et $\mathrm{al}^{15}$ found that consideration of multiple factors beside LVEF provide more accurate prediction of SCD and mortality; he developed a model identifying patients who meet criteria but are unlikely to have improvement in 2-year survival. In addition, often patients with an LVEF > 30\%, who would not receive an ICD based on guidelines are at high risk, with evidence that over half of patients who die suddenly have an $\mathrm{LVEF}>30 \% .^{33-35}$ In fact, current guidelines based on LVEF do not identify the majority of those who might benefit from an ICD.

In part because of perceived limitations of guidelines, many clinicians are not following them. One study reported a $9 \%$ compliance rate in suitable patients postmyocardial infarction. ${ }^{36}$ In contrast, a recent review of $>100,000$ patients in the National Cardiovascular Data Registry-ICD Registry found that $22.5 \%$ of ICDs did not meet evidence-based criteria. ${ }^{37}$ Even when clinicians are well familiar with and do wish to follow guidelines, lack of clarity about a patient's true LVEF, often documented solely as visual estimates "subject to bias and reader error," often differ depending on the imaging method chosen, creating uncertainty. ${ }^{32}$ In one study $31 \%$ of patients with $\mathrm{EF}<30 \%$ referred for ICD were not eligible after repeat imaging with ERNA showed a higher EF. ${ }^{38}$

Given the recognized problems with guidelines, a simple imaging method that can be used with routinely obtained HF clinical parameters, well described by Ketchum et al and consistent with much previous work, should help more effectively manage this prevalent and high morbidity/mortality condition. Compared with LVEF, imaging with autonomic tracers depicts cardiac pathophysiology closer to the underlying basis of arrhythmias. ${ }^{123} \mathrm{I}-m \mathrm{IBG}$, and perhaps PET tracers such as
${ }^{11} \mathrm{C}-\mathrm{HED}^{39,40}$ or an $\mathrm{F}-18$-based tracer under investigation, ${ }^{41}$ would be expected to more precisely determine risk.

Most agree that prospective clinical effectiveness trials studies examining the clinical utility of autonomic imaging with ${ }^{123} \mathrm{I}-m \mathrm{IBG}$ and other autonomic tracers are needed. Cardiac radionuclide imaging, while currently mostly confined to perfusion imaging, has promise in helping to show the underlying molecular basis of much cardiovascular disease, such as HF. ${ }^{42}$ Continuing the work of studies such as that of Ketchum et al has much potential for better directing patient management, thereby improving well-being and outcome.

\section{References}

1. Roger VI, Go AS, Lloyd-Jones DM, Benjamin EJ, Barry JD, Borden WB, et al. Heart disease and stroke statistics-2012 update: A report from the American Heart Association. Circulation 2012;125:e2-220.

2. Roger VI, Weston SA, Redfield MM, Hellermann-Homan JP, Killian J, Yawn BP, et al. Trends in heart failure incidence and survival in a community-based population. JAMA 2004;292: 344-50.

3. Levy D, Kenchaiah S, Larson MG, Benjamin EJ, Kupka MJ, Ho $\mathrm{KK}$, et al. Long-term trends in the incidence of and survival with heart failure. N Engl J Med 2002;347:1397-402.

4. Jessup M, Abraham WT, Casey DE, Feldman AM, Francis GS, Ganiats TG, et al. 2009 focused update: ACCF/AHA guidelines for the diagnosis and management of heart failure in adults: A report of the American College of Cardiology/American Heart Association Task Force on Practice Guidelines. J Am Coll Cardiol 2009;53:1343-82.

5. Bleumink GS, Knetsch AM, Sturkenboom MC, Straus SM, Hofman A, Deckers JW, et al. Quantifying the heart failure epidemic: Prevalence, incidence rate, lifetime risk and prognosis of heart failure The Rotterdam Study. Eur Heart J 2004;25:1614-9.

6. Bardy GH, Lee KL, Mark DB, Poole JE, Packer DL, Boineau R, et al. Amiodarone or an implantable cardioverter-defibrillator for congestive heart failure. N Engl J Med 2005;352:225-37.

7. Moss AJ, Zareba W, Hall WJ, Klein H, Wilber DJ, Cannom DS, et al. Prophylactic implantation of a defibrillator in patients with myocardial infarction and reduced ejection fraction. N Engl J Med 2002;346:877-83.

8. Hohnloser SH, Connolly SJ, Kuck KH, Dorian P, Fain E, Hampton $\mathrm{JR}$, et al. The defibrillator in acute myocardial infarction trial (DINAMIT): Study protocol. Am Heart J 2000;140:735-9.

9. Fisher JD, Ector HE. Relative and absolute benefits: Main results should be reported in absolute terms. Pacing and clinical electrophysiology: PACE 2007;30:935-7.

10. Lee DS, Krahn AD, Healey JS, Birnie D, Crystal E, Dorian P, et al. Evaluation of early complications related to De Novo cardioverter defibrillator implantation insights from the Ontario ICD database. J Am Coll Cardiol 2010;55:774-82.

11. Anderson KP. Estimates of implantable cardioverter-defibrillator complications: Caveat emptor. Circulation 2009;119:1069-71.

12. Anderson KP. Risk assessment for defibrillator therapy: II Trittico. J Am Coll Cardiol 2007;50:1158-60.

13. Sanders GD, Hlatky MA, Owens DK. Cost-effectiveness of implantable cardioverter-defibrillators. N Engl J Med 2005;353: 1471-80. 
14. Passman R, Kadish A. Shouldn't everyone have an implantable cardioverter-defibrillator? Circulation 2009;120:2166-7.

15. Buxton AE, Lee KL, Hafley GE, Pires LA, Fisher JD, Gold MR, et al. Limitations of ejection fraction for prediction of sudden death risk in patients with coronary artery disease: Lessons from the MUSTT study. J Am Coll Cardiol 2007;50:1150-7.

16. Levy WC, Mozaffarian D, Linker DT, Sutradhar SC, Anker SD, Cropp AB, et al. The Seattle Heart Failure Model. Prediction of survival in heart failure. Circulation 2006;113:1424-33.

17. May HT, Horne BD, Levy WC, Kfoury AG, Rasmusson KD, Linker DT, et al. Validation of the Seattle Heart Failure Model in a community-based heart failure population and enhancement by adding B-type natriuretic peptide. Am J Cardiol 2007;100:697-700.

18. Mozaffarian D, Anker SD, Anand I, Linker DT, Sullivan MD, Cleland JG, et al. Prediction of mode of death in heart failure: The Seattle Heart Failure Model. Circulation 2007;116:392-8.

19. Ketchum ES, Moorman AJ, Fishbein DP, Mokadam NA, Verrier ED, Aldea GS, et al. Predictive value of the Seattle Heart Failure model in patients undergoing left ventricular assist device placement. J Heart Lung Transplant 2010;29:1021-5.

20. Levy WC, Lee KL, Hellkamp AS, Poole JE, Mozaffarian D, Linker DT, et al. Maximizing survival benefit with primary prevention implantable cardioverter-defibrillator therapy in a heart failure population. Circulation 2009;120:835-42.

21. Ji SY, Travin MI. Radionuclide imaging of cardiac autonomic innervation. J Nucl Cardiol 2010;17:655-66.

22. Chirumamilla A, Travin MI. Cardiac applications of 123I-mIBG imaging. Semin Nucl Med 2011;41:374-87.

23. Merlet P, Valette H, Dubois-Randé J, Moyse D, Duboc D, Dove P, et al. Prognostic value of cardiac metaiodobenzylguanidine in patients with heart failure. J Nucl Med 1992;33:471-7.

24. Agostini D, Verberne HJ, Burchert W, Knuuti J, Povinec P, Sambuceti G, et al. I-123-mIBG myocardial imaging for assessment of risk for a major cardiac event in heart failure patients: Insights from a retrospective European multicenter study. Eur J Nucl Med Mol Imaging 2008;35:535-46.

25. Verberne HJ, Brewster LM, Somsen GA, van Eck-Smit BL. Prognostic value of myocardial 123I-metaiodobenzylguanidine (MIBG) parameters in patients with heart failure: A systematic review. Eur Heart J 2008;29:1147-59.

26. Jacobson AF, Senior R, Cerqueira MD, Wong ND, Thomas GS, Lopez VA, et al. Myocardial iodine-123 meta-iodobenzylguanidine imaging and cardiac events in heart failure. Results of the prospective ADMIRE-HF (AdreView Myocardial Imaging for Risk Evaluation in Heart Failure) study. J Am Coll Cardiol 2010;55:2212-21.

27. Travin M, Ananthasubramaniam K, Henzlova MJ, Clements IP, Amanullah A, Jacobson AF. Imaging of myocardial sympathetic innervation for prediction of cardiac and all-cause mortality in heart failure: Analysis from the ADMIRE-HF trial. Circulation 2009;120:S350.
28. Ketchum ES, Jacobson AF, Caldwell JH, Senior R, Cerqueira MD, Thomas GS, et al. Selective improvement in Seattle heart failure model risk stratification using iodine-123 meta-iodobenzylguanidine imaging. J Nucl Cardiol 2012. doi:10.1007/s12350-012-9603-0.

29. Tricoci P, Allen JM, Kramer JM, Califf RM, Smith SC Jr. Scientific evidence underlying the ACC/AHA clinical practice guidelines. JAMA 2009;301:831-41.

30. Diamond GA, Kaul S. Bayesian classification of clinical practice guidelines. Arch Intern Med 2009;169:1431-5.

31. Kadish A, Dyer A, Daubert JP, Quigg R, Estes NA, Anderson KP, et al. Prophylactic defibrillator implantation in patients with nonischemic dilated cardiomyopathy. N Engl J Med 2004;350:2151-8.

32. Myerburg RJ. Implantable cardioverter-defibrillators after myocardial infarction. N Engl J Med 2008;359:2245-53.

33. de Vreede-Swagemakers JJ, Gorgels AP, Dubois-Arbouw WI, van Ree JW, Daemen MJ, Houben LG, et al. Out-of-hospital cardiac arrest in the 1990's: A population-based study in the Maastricht area on incidence, characteristics and survival. J Am Coll Cardiol 1997;30:1500-5.

34. Gorgels AP, Gijsbers C, de Vreede-Swagemakers J, Lousberg A, Wellens HJ. Out-of-hospital cardiac arrest- the relevance of heart failure. The Maastricht Circulatory Arrest Registry. Eur Heart J 2003;24:1204-9.

35. Stecker EC, Vickers C, Waltz J, Socoteanu C, John BT, Mariani R, et al. Population-based analysis of sudden cardiac death with and without left ventricular systolic dysfunction: Two-year findings from the Oregon Sudden Unexpected Death Study. J Am Coll Cardiol 2006;47:1161-6.

36. Pertzov B, Novack V, Zahger D, Katz A, Amit G. Insufficient compliance with current implantable cardioverter defibrillator (ICD) therapy guidelines in post myocardial infarction patients is associated with increased mortality. Int J Cardiol 2011. doi:10.1016/ j.ijcard.2011.10.132

37. Al-Khatib SM, Hellkamp A, Curtis J, Mark D, Peterson E, Sanders GD, et al. Non-evidence-based ICD implantations in the United States. JAMA 2011;305:43-9.

38. Krahn AD, Hoch JS, Rockx MA, Leong-Sit P, Gula LJ, Yee R, et al. Cost of preimplantation cardiac imaging in patients referred for a primary-prevention implantable cardioverter-defibrillator. Am J Cardiol 2008;102:588-92.

39. Henneman MM, Bengel FM, van der Wall EE, Knuuti J, Bax JJ. Cardiac neuronal imaging: Application in the evaluation of cardiac disease. J Nucl Cardiol 2008;15:442-55.

40. Fallavollita JA, Canty JM Jr. Dysinnervated but viable myocardium in ischemic heart disease. J Nucl Cardiol 2010;17:1107-15.

41. Yu M, Bozek J, Lamoy M, Guaraldi M, Silva P, Kagan M, et al. Evaluation of LMI1195, a novel 18F-labeled cardiac neuronal PET imaging agent, in cells and animal models. Circ Cardiovasc Imaging 2011;4:435-43.

42. Morrison AR, Sinusas AJ. Advances in radionuclide molecular imaging in myocardial biology. J Nucl Cardiol 2010;17:116-34. 